\title{
Filosofia da práxis, pós-colonialismos e Serviço Social no estudo da América Latina
}

\author{
Joelcio Jackson Lima Silva
}

Telma Cristiane Sasso de Lima²

Elídio Alexandre Borges Marque ${ }^{3}$

\section{Resumo}

O ensaio teórico revisa algumas fontes que exploram a corrente de pensamento pós-colonial latino-americano, identificando elementos de influência marxista que permitiriam uma aproximação entre "estudos decoloniais" e "filosofia da práxis gramsciana". Destacam-se as particularidades interpretativas produzidas sobre a realidade socioeconômica e político-cultural da América Latina, ainda hoje pouco exploradas. Preliminarmente, a categoria da "tradutibilidade" auxilia na síntese crítica pretendida, embora as pesquisas sobre o tema ainda sejam escassas, especialmente no serviço social, pois se for possível ampliar nosso léxico interpretativo de forma orgânica a transformar substantivamente a prática profissional concretizaremos ações mais coerentes às lutas das classes subalternas.

\section{Palavras-chave}

Filosofia da práxis; Pós-colonialismo; Tradutibilidade; Serviço Social.

Philosophy of praxis, post-colonialisms and Social Work in the study of Latin American

\begin{abstract}
The essay reviews some sources that explore the Latin American post-colonial current of thought, identifying elements of Marxist influence that would allow an approximation between "decolonial studies" and "gramscian praxis's philosophy". They stand out for the interpretative particularities produced on the socioeconomic and political-cultural reality of Latin America, which are still little explored today. Preliminarily, the category of "tradutibility" assists in the desired critical synthesis, although research on the topic is still scarce, especially in social work, because - if it is possible to expand our interpretive lexicon in an organic way to substantially transform professional practice - we will implement actions more consistent with the struggles of the subalterns classes.
\end{abstract}

\section{Keywords}

Philosophy of praxis; Post-colonialism; Tradutibility; Social Work

Artigo recebido: março de 2021

Artigo aprovado: maio de 2021 


\section{Introdução}

Na América Latina, as relações de produção capitalista foram introduzidas a fórceps ao longo do século XX. As elites locais e o cenário político-econômico internacional aprofundaram a dependência dos países latino-americanos às demandas primárias dos grandes centros capitalistas. A emergência de classes sociais sob o trabalho assalariado urbano ocorreu de maneira caótica e aligeirada sem reparação histórica na suplantação do regime escravagista, mormente no Brasil. Grosso modo, a industrialização precoce foi incentivada por meio da grande inserção de capitais norte-americanos que, até a década de 1930, se colocava como alternativa econômica e comercial ao domínio europeu no continente e também à expansão socialista vinda do Leste europeu com o socialismo soviético (SADER, 2000).

O processo de industrialização urbana teve início no Chile cuja população compunha um contingente de trabalhadores rurais, da mineração de carvão e do extrativismo de cobre. A tecnificação no extrativismo de matérias primas para exportação, impulsionou a mecanização no setor agrícola e o investimento em indústrias têxteis. Dessas fábricas, emanou um insurgente proletariado urbano organizado a partir de informações e adesões ao Partido dos Trabalhadores Socialistas do Chile (1912) e ao Partido Comunista (1922) (CASTRO, 1987).

A organização sindical urbana e, posteriormente, a formação de Partidos trabalhistas ora influenciados por ideais liberais/socialdemocratas, ora inspirados em debates e experiências propagados na Terceira Internacional Comunista na intenção de fortalecer e expandir o engajamento crítico e a organização política na classe trabalhadora, especialmente após a Revolução Russa (SADER, 2000). Aliado à conformação de novas relações de produção, transformavam-se também as relações socioculturais diante de novas influências ídeo-políticas, simultaneamente, processavam-se novas necessidades individuais e coletivas que se somavam aos velhos carecimentos/demandas socioeconômicas básicas de subsistência (CASTRO, 1987). 
A criação de uma institucionalidade socioestatal com mão de obra técnico-científıca em diferentes e novas áreas também era necessária para a concretização do projeto capitalista modernizador na latino-américa. Os novos aparelhos estatais inspiravam-se nas experiências Iluministas europeias e na independência das Colônias Norte-americanas nos séculos anteriores, alterando, em parte, algumas formas de enfrentar os problemas e carecimentos sociais. Gradativamente, conheciam-se melhor as ações e serviços profissionais técnicos/laicas ou filantrópicos (enfermeiras, médicos, visitadoras sociais etc.) destinados a ordenar a pobreza urbana e à organização das demandas operárias (MARTINELLI, 1997).

As legislações aprovadas em 1924, no Chile, exemplificam como ocorreu a institucionalização pioneira de direitos e serviços focados na proteção mínima da mão de obra assalariada urbana por meio de Leis referentes: à previdência social, ao seguro operário obrigatório, à habitação popular, ao direito de greve, à sindicalização legal, à proteção do trabalho infantil e feminino etc. Signifıcava que se modifıcaram, nos países da América Latina, o sentido legal/institucional do Estado cujas vanguardas se esforçavam em constituir Nações, absorvendo os princípios liberais no enfrentamento da subjugação Colonial, até então, calcada no extrativismo e no escravagismo (CASTRO, 1987).

No entanto, tanto na Europa quanto na América, o social sempre foi um campo em disputa, especialmente entre a Igreja Católica e os embrionários serviços públicos tecnificados/laicos e/ou de orientação filantrópica. A profıssão de Serviço Social latino-americana se desenvolveu por meio de setores da Igreja Católica que absorveram estrategicamente as necessidades de expansão capitalista, aparentemente modernizadas pela Ação Social Católica. Esta herdeira da Contrarreforma, estabeleceu atividades fortemente persecutórias e obscurantistas de modo a dar vazão aos interesses sociopolíticos do clérigo católico, arregimentando fiéis leigos na execução de serviços e da caridade organizada de modo a recuperar parte da influência intelectual da Igreja (IAMAMOTO; CARVALHO, 2000). 
A “modernização" de setores da Igreja Católica ocorreu amparado nas Encíclicas Papais: Rerum Novarum e Quadragesimo Anno que justificavam a colagem entre a moral religiosa católica com os interesses utilitaristas dos capitalistas cuja expressão de sua vontade política estava reunida nos novos aparatos estatais e em novas leis e serviços que buscavam atender e controlar a classe trabalhadora por meio de respostas organizadas que reconheciam algumas de suas reivindicações por direitos (CASTRO, 1987).

Nesse ponto, inferimos que as bases gramscianas auxiliam na compreensão histórica do Serviço Social como “intelectual orgânico" sobre a visão de mundo conservadora, bem como sobre os motivos e as escolhas epistêmicas de sua profissionalização na América Latina. Além disso, o mergulho de Gramsci no movimento socialista russo, sobretudo na análise do legado leninista da Revolução Russa, ampliou o sentido atribuído à "região" e ao "regionalismo" cujas preocupações teórico-práticas apontavam para o estudo da "cultura"4 sob bases científicas igualmente refinadas àquelas aplicadas pelos marxistas ortodoxos clássicos no estudo das estruturas econômicas e de Estado burguês. A cultura nos escritos gramscianos constitui-se em elemento fundamental na catalisação dos processos históricos e revolucionários (DIAS, 2017).

Neste artigo, exploramos aspectos do pensamento gramsciano em seu legado latino-americano em relação a algumas fontes da corrente pós-colonial. Trata-se de um ensaio teórico e, como tal, reúne sistematizações iniciais que podem disponibilizar outras fontes teórico-conceituais para o Serviço Social, sobretudo diante de seu compromisso na apropriação crítica desses referenciais para a leitura dos dilemas contemporâneos, considerando a função social da profıssão no processo individual e coletivo de contribuir para a organização ídeo-política das classes subalternas em prol da "reforma intelectual e moral" necessária para construirmos uma sociabilidade revolucionária, concretamente igualitária. 
A próxima seção contextualiza historicamente o desenvolvimento teórico-prático dos referenciais que compõem a corrente de pensamento conhecida como "pós-colonial", na sequência ensaiamos uma síntese considerando a categoria gramsciana de "tradutibilidade", tanto para pensarmos se é possível uma síntese crítica ao analisarmos à realidade latino-americana e ao considerarmos a função teórico-prática de intelectual orgânico do serviço social.

\section{A Corrente Interpretativa Pós-colonial: breve contextualização}

A modernidade, conforme resume Acanda (2006, p. 51), resulta "[...] de processos de mudanças sociais na estrutura econômico-produtiva, na organização político-institucional e em seus paradigmas simbólicos legitimadores, bem como na interação entre esses processos". Trata-se de um período histórico amparado pelos princípios fundantes do individualismo, da diferenciação/hierarquização (calcada nos modelos binário e cartesiano), da racionalidade de todos os aspectos da vida, da subordinação econômica/economicismo e da expansão geográfica e cultural.

Sua dinâmica assenta-se na tríade: desenvolvimento e expansão capitalista, imposição imperialista do liberalismo e estabelecimento do colonialismo. A universalização dessa tríade e da hierarquização das relações humanas gestaram o processo de mundialização do sistema capitalista, legitimando e justificando as ações concretas que produziram: genocídios, epistemicídios nativos e subjugação racial (PINTO, 2020).

Gradativamente, consolidaram-se narrativas naturalizantes acerca do progresso técnico-científico e da harmonia social, mascarando as incontáveis tensões que fomentavam levantes reivindicativos diante da mercadorização de todas as esferas de vida humana. Na América Latina, os movimentos organizaram-se em torno de "vanguardas ilustradas" geralmente oriunda de famílias europeias colonizadoras ou de círculos corporativos militares que tensionavam a pauta pela "independência das colônias europeias", vocalizando o processo político 
desencadeado desde o sec. XVIII com as lutas contra a escravidão e pela formação de Estados-Nação. Cabe enfatizar que, no Continente Africano e na Ásia, esses levantes por "independência do colonialismo europeu" só se intensificaram após Segunda Guerra Mundial em meados do século XX (LOSURDO, 2006; PINTO, 2020).

A disputa entre Ocidente capitalista e Oriente socialista também fomentou uma nova "alteridade planetária" que rebatizou a geopolítica mundial: as antigas Metrópoles colonizadoras foram denominados como "Primeiro Mundo", porque envolvia "países democráticos de economia capitalista avançada". O "Segundo Mundo" era composto pelo bloco de países cujas revoluções tentaram constituir uma política socioeconômica planificada sob bases ídeo-culturais socialistas. No "Terceiro Mundo" ficaram os países formados a partir das antigas Colônias extrativistas, empobrecidas e economicamente dependentes da economia e da política mundial e disputados pelos outros blocos (PINTO, 2020).

Nesse processo histórico, havia bandeiras políticas próprias no "Terceiro Mundo" reivindicadas por seus intelectuais que imprimiram novos significados à "liberdade do país e do povo". Isso gestou diferentes interpretações críticas sobre a herança colonial introjetada na América Latina em quatro séculos de subjugação cultural e de extrativismo das riquezas naturais (PINTO, 2020). Propunham-se novas lentes explicativas sob as bases das experiências históricas dos povos originários subjugados e de suas filosofias ancestrais, fase denominada de "pós-colonialismo" por dois motivos:

O primeiro diz respeito ao tempo histórico posterior aos processos de descolonização do chamado "terceiro mundo", a partir da metade do século XX. Temporalmente, tal ideia refere-se, portanto, à independência, libertação e emancipação das sociedades exploradas pelo imperialismo e neocolonialismo - especialmente nos continentes asiático e africano. A outra utilização do termo se refere a um conjunto de contribuições teóricas oriun- 
das principalmente dos estudos literários e culturais, que a partir dos anos 1980 ganharam evidência em algumas universidades dos Estados Unidos e da Inglaterra (BALLESTRIN, 2013, p. 90).

"Colonial" refere-se às diferentes opressões praticadas desde a fase de subjugação pelos países europeus, incluindo práticas que não são consequências diretas da herança colonial, mas que foram imprescindiveis para a consolidação do próprio sistema capitalista que soube absorver o tradicionalismo colonial às bases modernizadoras culturais e econômicas liberais. Já o "Pós-colonialismo" refere-se às inúmeras correntes de pensamentos diretamente ligadas às lutas e aos movimentos políticos anticoloniais, logo, tratam-se de referenciais que criticaram de diferentes pontos a tríade da modernidade tal como significada pelas correntes de pensamento europeias. Mesmo sob perspectivas por vezes conflitantes, esta corrente apresentava alguns pontos de confluência: "caráter discursivo do social, o descentramento das narrativas e dos sujeitos contemporâneos, métodos de desconstrução dos essencialismos e propostas de uma epistemologia crítica às concepções dominantes de modernidade" (BALLESTRIN, 2013, p. 90).

Historicamente, apontam-se três fases do pós-colonialismo: a primeira envolveu as produções classificadas como "pós-colonialismo anticolonial" 5 desencadeada por "intelectuais, ativistas e lideranças, deixando uma produção dispersa, não necessariamente acadêmica, institucionalizada e disciplinada" (BALLESTRIN, 2017, p. 509). Também fortemente influenciada pelos estudos: da psicanálise, do pan-africanismo, do pensamento afrodiaspórico e do marxismo revolucionário que já levantavam problematizações sobre a identidade e a função do racismo no colonialismo e na sustentação do imperialismo capitalista (BALLESTRIN, 2017).

A segunda fase refere-se ao "pós-colonialismo canônico" ou "pós-estrutural"6 que reforçou a corrente pós-colonialista como um movimento epistêmico, intelectual e político. A influência recebida do "pós-estruturalismo" e das "teorias pós-modernas" gerou análises 
centradas nas "estruturas mentais, ideológicas e teóricas do colonialismo" cujo objetivo era desconstruir essas estruturas desnudando os elementos centrais do projeto colonial/imperial. No entanto, foi bastante difusa na construção dessa crítica, pois tentou universalizar as fontes do "pós-colonialismo canônico", contradizendo-se ao restaurar pontos epistêmicos da própria modernidade, até então, fortemente criticados (BALLESTRIN, 2017).

Em contraponto, os estudos sul-asiáticos do período (década 1970) ocorriam sob o prisma marxista de Ranajit Guha que formou o Grupo de Estudos Subalternos (Subaltern Studies), elaborando novos approaches que conformaram uma corrente teórica específica dentro desse debate e fortemente vinculada à realidade da Índia. O grupo teve grande diálogo com fontes do pós-colonialismo cujas pesquisas estavam conectadas aos "pós-colonialismo anticolonial" e marxismos. Dos marxismos, houve maior uso e interpretação das análises de Gramsci (ACUIAR, 2016b). O Subalten Studies formou uma historiografia pós-colonial e classista pela perspectiva dos sujeitos subalternos, sua principal contribuição consistiu na crítica acerca das “identidades" significadas a partir das relações de poder econômico e cultural que rompem/ultrapassam a delimitação geográfıca quando se pretende explicar as relações socioculturais e o exercício do poder político-econômico entre as Nações hegemonizadas pelo Capitalismo (BALLESTRIN, 2017). Conforme salienta Neves (2010):

[...] como variante especificamente indiana dos Estudos Pós-Coloniais, alargaram gradualmente a sua esfera de influência, até abrangerem, hoje em dia, os estudos sobre os «subalternos de todo o mundo», Ocidente incluído, e nomeadamente sobre todos os grupos marginalizados pela história, como as mulheres, os exilados, os refugiados, as minorias étnicas, religiosas, linguísticas [...] (NEVES, 2010, p. 60).

Para Neves (2010), os estudos de Gramsci e do Subatern Studies foram impulsionados por derrotas políticas: experimentadas nas lutas 
operárias italianas e nas de independência indiana. Os pesquisadores indianos partiram da premissa gramsciana: a falta de organização torna os grupos subalternos politicamente impotentes e a hegemonia guiada pelos grupos intelectuais representantes do poder político-econômico vigente gera uma força política e cultural penetrante que governa sob consenso, mas segue violando àqueles que são subalternizados.

Embora o Subatern Studies colocasse em debate temas fundamentais para a "esquerda política", gradualmente, ao longo do tempo, também perdeu de vista a perspectiva marxista e gramsciana sobre as possibilidades concretas de construção ativa da história e de transformação da própria condição pelos subalternos. Houve inúmeras críticas sobre seus estudos, fortalecidas pelo questionamento do viés de "imperialismo" existente nas análises culturais produzidas, uma vez que os críticos consideravam que os autores asiáticos não teriam rompido adequadamente com as fontes eurocêntricos/Norte globais (ACUIAR, 2016b).

Na América Latina, a influência desse debate foi consolidada após a criação do Grupo de Estudos Subalternos Latino-americanos (década 1990), procurando tecer uma incorporação crítica dos argumentos do pós-colonialismo no Continente, principalmente no trato de questões como: independência, libertação e emancipação das sociedades exploradas pelo imperialismo e neocolonialismo. Foi um movimento crítico dedicado à superação das lacunas presentes nos estudos elaborados pelo grupo norte-americano denominado Foreign Culture ${ }^{7}$ (Culturas Estrangeiras), buscando repolitizar suas análises (ACUIAR, 2016b).

Sob a leitura do grupo latino-americano, a crítica às fontes "pós-coloniais" questionava a importação e as menções a autores como: Foucault, Derrida, Gramsci e Guha. Essa crítica concluía que: tanto o grupo asiático quanto o grupo norte-americano de "estudos subalternos" não foram capazes de aprofundar e radicalizar a crítica ao eurocentrismo (BALLESTRIN, 2013). O aprofundamento crítico levou às discordâncias internas e dissolução do Grupo Latino-Americano, 
demarcando o início da terceira fase denominada "decolonial" que retomou a "colonialidade" como conceito-chave ao significá-la reconhecendo que nela coabitam estruturas e padrões de poder coloniais mesmo que tenhamos vivido um processo de "independência" e de formação de Nações na latino-américa. O marco do "giro decolonial" ocorreu com a criação do grupo de investigação Modernidade/Colonialidade, em 1998, especialmente a partir das publicações de Anibal Quijano (BALLESTRIN, 2017).

A recuperação de fontes latino-americanas da fase do "pós-colonialismo anticolonial" levou ao afastamento do "pós-colonialismo canônico" na intenção de radicalizar/revolucionar, na América Latina, a crítica à modernidade eurocêntrica, apontando enfaticamente seus prejuízos interpretativos uma vez que a "colonialidade" não poderia ser dissociada da ideia de "modernidade europeia". Os estudos "decoloniais" referenciaram-se em pensadores latino-americanos, resgatando diferentes interpretações, especialmente de produções elaboradas a partir da Filosofia da Libertação, da Teoria da Dependência, da Teoria do Sistema-mundo, dos Grupos de estudos subalternos, da Filosofia Afro-caribenha e do feminismo latino-americano ${ }^{8}$ (BALLESTRIN, 2017; AGUIAR, 2016b).

No entanto, a elaboração de uma crítica purista contra a modernidade eurocêntrica gerou dúvidas mútuas entre marxistas e pós-colonialistas, o prefixo "pós" foi considerado ambíguo porque transmitia a ideia de que o colonialismo poderia ser superado. Isso exacerbou o "culturalismo" como cerne das análises produzidas, sem que os autores percebessem que a ênfase excessiva na cultura deixava de problematizar o cerne do sistema material e econômico capitalista (BALLESTRIN, 2017). Consequentemente, a desconexão produzida entre colonialismo e imperialismo pela crítica radical de alguns autores "decoloniais" prejudicou a produção intelectual contra a modernidade eurocêntrica. Contudo, a corrente do "pós-colonialismo" absorveu de maneira autoral muitas influências marxistas, principalmente na fase 
do "pós-colonialismo anticolonial", embora esta também tenha sido questionada pelos autores decoloniais.

Ballestrin (2017) aponta que as críticas decoloniais contra o uso de fontes marxistas foram seletivas quando observa que a maioria dos autores decoloniais iniciaram seus estudos a partir das produções do grupo Modernidade/Colonialidade, participando ainda de movimentos políticos inspirados nos ideais marxistas e referenciando fontes oriundas da Teoria da Dependência, do Desenvolvimento, da Filosofia da Libertação, do Sistema-mundo etc. fortemente influenciadas pelo legado crítico do materialismo histórico e dialético.

Concordamos com Ballestrin (2017) quando afırma que a separação entre os estudos decoloniais e os estudos marxistas decorreu de uma interpretação equivocada e artifıcial, tendo em vista que os processos históricos são intercambiantes e a realidade dialética, mesmo quando teorizada seus conceitos e categorias não ficam muito tempo fixados. Com base nessa afirmação, buscamos mapear se existem aspectos de contato entre a filosofia da práxis gramsciana e o pós-colonialismo latino-americano, pois nos parece que essa relação possibilitaria novos nexos interpretativos e interventivos por parte do serviço social no exercício da função de intelectual orgânico às lutas das classes subalternas.

\section{Filosofia da Práxis Gamsciana e Pós-colonialismo Latino-americano: a "tradutibilidade" em questão no estudo das fontes decoloniais}

Ao tomarmos a filosofia da práxis gramsciana como lente para a compreensão e ação na contemporaneidade latino-americana mediada pelo legado dos estudos decoloniais, destacamos a categoria gramsciana de "tradutibilidade" porque como um processo orgânico de interpretação, reinterpretação e transformação de teorias só pode ocorrer quanto existem concretamente bases sociais e de concepção de mundo semelhantes (BOOTHMAN, 2017).

A "tradutibilidade" foi utilizada por Gramsci em duas situações: a) referindo a "tradutibilidade das linguagens natural/cultural"; e b) de- 
batendo a tradutibilidade das linguagens científicas/filosóficas (BOOTHMAN, 2017). Interessa-nos, neste ensaio, esta última significação, porque consideramos que pode ser uma das chaves interpretativas capaz de nos auxiliar no estudo da decolonialidade latino-americana.

No curso do desenvolvimento de seus escritos, Gramsci considera que a tradução entre linguagens científica/filosóficas é possível, mas não da maneira realizada pelos expoentes marxistas e pelos conservadores de sua época porque não se trata de uma simples e resumida incorporação de categorias/conceitos colhidos em outros paradigmas, mas a sua reinterpretação e transformação conforme as condições socioculturais dos eventos históricos que se pretende relacionar, explicar ou traduzir. Esse processo envolve a partilha e a compreensão profunda dos fundamentos de uma concepção de mundo, dentro da qual podem coexistir diferentes narrativas, mas nunca projetos societários conflitantes porque todas devem convergir, em última instância, para a construção de uma sociabilidade humanística, crítica e concretamente igualitária (BOOTHMAN, 2017).

Portanto, a filosofia da práxis gramsciana resulta de um processo de tradutibilidade do legado de Marx e Engels (Diamat) e das interpretações marxistas oriundas da Segunda Internacional Comunista e da Revolução Russa em relação aos desafios organizativos dos trabalhadores urbanos diante das representações político-parlamentares socialdemocratas na fase monopolista do Capitalismo ocidental. Para Lacorte (2017) a tradutibilidade só ocorre quando sintetiza, na teoria, aspectos coletados a partir de fatos históricos instauradores de rupturas que nos exigem pensar e agir sobre o presente de maneira crítica e nova diante da:

[...] possibilidade de traduzir entre dois elementos/atividades (a prática e a teoria) - que tradição de pensamento ocidental não admite, pois separa as duas e as torna duas substâncias metafisicamente distintas - é primeiramente um fato histórico (ou mais do que um, na realidade), mas é por isso que faz sentido teorizar sobre ele [...]. (LACORTE, 2017, p. 50). 
A filosofia da práxis compreende intimamente a dialética da realidade porque a teoria (superestrutura) só consegue viver concretamente se for capaz de ter alcance prático (estrutura), ou se, na condição de prática, for capaz de desenvolver-se com alcance teórico e de difusão cultural. Para Cramsci, a teoria é a própria prática em momento de elaboração (concreto pensado). Portanto, apenas quando a classe revolucionária estabelece condições sociopolíticas para iniciar um processo de reforma intelectual e moral, a teoria pode se tornar vontade coletiva porque passa a ser compreendida pelas massas que transformam seus modos de agir e de conviver em sociedade, gerando também todo um novo léxico conceitual e cultural (CHABALGOITY, 2018; LACORTE, 2017).

É a partir dessa compreensão que esboçamos aqui os pontos de contato que, preliminarmente, avaliamos existir entre a filosofia da práxis gramsciana e o pós-colonialismo, particularmente na interpretação dos estudos decoloniais. Parece-nos que ambas realizam um giro interpretativo do mundo a partir do ponto de vista dos grupos subalternos cuja essência exige ação crítica sobre a realidade e a cultura para revolucioná-las. Inferimos que o ponto nodal desse contato reside na crítica à tríade da modernidade tal como concebida e explicada pelos paradigmas teóricos europeus.

Outro ponto de contato parece-nos ser a recuperação da dialética para apreender a dinâmica da realidade e das relações humanas que são frutificadas ao longo de processos históricos e de pactuações culturais entre diferentes povos em relação: ora pelo domínio da força bélica, ora pela construção de narrativas gestoras da aculturação necessária para o exercício do domínio da cultura de um povo sobre a de outros. Importante destacar que, na corrente pós-colonial, essa característica é mais evidente na fase dos estudos decoloniais cujo ponto de partida reiterava que: não é possível se desfazer de todas as influências consolidadas na América Latina ao longo do período Colonial, mas é possível pautar um novo legado teórico-metodológico 
e ético-político a partir dos fatos históricos concretos forjados nesse território (CHABALGOITY, 2018).

Em nossa análise preliminar, filosofia da práxis gramsciana e estudos decoloniais formariam juntas uma rica base referencial porque partilham afınidades ético-políticas importantes, podendo auxiliar contemporaneamente na melhor apreensão dos nossos erros históricos, como também para agirmos ativamente para superarmos nossa condição de grupos subalternos. Em alguma medida, são teorizações que reposicionam: a centralidade colonização e dinâmica de classes, bem como de enfoque sobre sujeitos e processos emancipatórios, proletariado e povos colonizados/“subalternos”, etc.

As fontes decoloniais exploram ainda um giro interpretativo sobre as formas político-organizativas calcadas em partidos e lutas operárias urbanas, reconhecendo como igualmente legítimas e como parte substantiva da condição revolucionária: as múltiplas formas de resistência decolonial, diferenciando-se radicalmente na relação interpretativa e de ação com a questão da "modernização" sob o prisma europeu. Tal compreensão é esboçada em parte dos escritos que fundamentam a filosofia da práxis, sendo desenvolvida nas obras de autores decoloniais latino-americanos, muitos deles reconhecem que Mariátegui se esforçou em enfrentar essas questões a partir de um "marxismo latino-americano" muito antes de falarmos em "pós-colonialismos".

Ocupar-se dessas matrizes teórico-práticas é importante, ainda hoje, porque compelem e prospectam a luta organizada, racionalizada e atenta aos pactos políticos coletivos herdados, sem perder de vista a revolução como essência na construção de relações socioculturais e econômicas igualitárias. Parece-nos que podem ser traduziveis, tal como propunha Gramsci ao se referir a "tradutibilidade das linguagens científicas/filosóficas, conforme destaca Chabalgoity:

O pensamento decolonial necessita de um marxismo vivo, não-ortodoxo, não-estruturalista, que considere o ponto de partida ontológico do Sul, da mesma forma que o marxismo necessita 
de uma ontologia do ser social para que não se torne determinista ou mecanicista. A reflexão ontológica não nos deixa olvidar que as condições materiais e culturais de dominação caminham juntas, o que faz a construção de identidade dos sujeitos coletivos assumir lugar de destaque, a ser construída na própria práxis de luta pela transformação (CHABALGOITY, 2018, p. 84).

O pluralismo teórico é o motor vivo herdado da Filosofia da Ciência moderna. O que está em questão: são as maneiras pelas quais escoIhemos encaminhar nossas atividades técnico-científicas e os projetos ético-políticos que defendemos como visão de futuro capaz de decodificar o devir histórico e agir no presente sem recorrer ao cartesianismo/positivismo/utilitarismo em suas dicotomizações e hierarquizações no trato das inúmeras áreas de conhecimento que foram elaboradas arduamente pela humanidade ao longo de milênios de choques culturais, subjugações e genocídios.

Inferimos que a defesa de uma ruptura com a modernidade euro-centrada refere-se a um tipo de produção de conhecimento científıco: aquela que aparta história e política, intencionando a purificação da existência humana por intermédio da abstração teórico-conceitual de grandes narrativas/correntes teóricas. Então, filosofia da práxis e estudos decoloniais podem ser consideradas traduziveis quando resgatamos a essência do materialismo histórico e dialético que compele à produção de novas sínteses sobre os aspectos vividos e teorizados porque são bases teórico-práticas capazes de contribuir para apreensões críticas mais consistentes acerca dos fatos histórico-culturais e dos dilemas latino-americanos presentes.

\section{Síntese preliminar e a démarche histórico-profissional do Serviço Social latino-americano}

Reconhecemos que o processo de interpretação científıco-filosófica nos transversaliza a partir da apropriação dos referenciais eurocêntricos sobre a modernidade e o capitalismo. A corrente "pós-colonial”, mes- 
mo com diferentes variantes, foi elaborada a partir de interpretações autorais de fatos históricos, pautando questões culturais e territoriais ausentes nas fontes marxistas porque muitos de seus expoentes não conheceram essa realidade a fundo, quando a mencionavam ainda as submetiam aos aspectos econômicos ou críticas macrossociais pretensamente universalizantes do ponto de vista das experiências europeias.

Neste ensaio, ao considerarmos as pistas aqui reunidas, há um árduo caminho a percorrer, quando tratamos das bases gramscianas e dos estudos decoloniais como fontes que filosofam a partir da vida popular em sua concretude, dissenso e até mesmo confusão. São teorias que não abdicaram da unidade subjetivo-objetivo, individual-coletivo, material-simbólico, estrutura-superestrutura, teoria- prática etc., ou seja, os princípios epistêmicos fundantes que as movimentam vinculam-se organicamente às vicissitudes e resistências das massas populares cujas organização e educação ético-política não fica retida em vanguardas ou em importações de narrativas de aculturação. As críticas empreendidas são acompanhadas por prospecção de ações realistas e necessárias para disseminar uma certa consciência/ideologia coletiva materialmente possível de se realizar porque se dedica a transformar substantivamente todo o mundo a partir da compreensão do legado existente.

Essa ação crítico-transformadora não se restringe às análises teóricas sobre as fontes até aqui mencionadas, implica necessariamente a construção de formas concretas de expressar/de realizar os ideais mais refinados elaborados pela humanidade, aqueles que pensam a todos de maneira igualitária e com capacidade de se desenvolver cooperativamente tanto em sentido individual quanto no coletivo, revolucionando as funções sociais e construindo novos sistemas simbólicos/ culturais, socioeconômicos e jurídico-políticos.

Para tanto, ainda precisamos encarar que o processo de Colonização da América Latina deixou como herança: uma classe dominante e uma burguesia conservadora, eivada culturalmente pelo moralismo 
católico e de seus referenciais europeus. Aspecto que permeou a formação das primeiras escolas de Serviço Social e do perfil profissional elitista das primeiras "reformadoras sociais" (KISNERMANN, 1983). As ações de assistência aos pobres, apesar do esforço em tecnificá-las sob bases científicas liberais, foram estruturadas sob forte viés compassivo, disciplinar e utilitarista cuja meta era garantir a "reforma de caráter" de pobres (trabalhadores assalariados ou não), apaziguando os conflitos da luta de classes (CAPONI, 2000).

Historicamente, constata-se que as ações profissionais de assistentes sociais estiveram hegemonicamente ancoradas em epistemes que reforçaram o projeto societário da classe dominante, auxiliando na reprodução de um status quo estruturalmente desigual e com forte viés Colonial. Nesse contexto, o serviço social se consolidou como profıssão, mesclando técnicas empiristas/utilitaristas às práticas morais de caridade religiosa exercidas desde a colonização por diferentes confrarias da Igreja Católica (MARTINELLI, 1997). Essa influência predominou desde a fundação das primeiras escolas que ocorreu sob o direcionamento da União Católica Internacional de Serviço Social (1925) até as ditaduras latino-americanas (CASTRO, 1987)

As obras de Gramsci (1891-1937) foram redigidas no contexto de intensos conflitos sociais e territoriais entre as Guerras Mundiais do século XX, revelando uma sociedade marcada por disputas abertas corpo a corpo nas trincheiras de guerra, ou por meio da inculcação de narrativas ideológicas fomentadas pela imprensa jornalística, rádio, diferentes frentes intelectuais/profissionais e, posteriormente, pela massificação da propaganda política que coordenou esforços para naturalizar o "progresso capitalista", justificando confrontos bélicos e regimes totalitários, sobretudo em regiões geopolíticas periféricas nas quais esse progresso consistia numa casca frágil e superficial de modernização que revestiu o conservadorismo (GUILHERME, 2008).

A produção intelectual de Gramsci é influenciada pela sua época e compõe um itinerário crítico e engajado no enfrentamento realista/ra- 
cional dos limites vividos no seio da militância política socialista ao lado das massas de trabalhadores urbanos. A partir do estudo das obras de Lenin, Gramsci ampliou o sentido dos conceitos: "região" e "regionalismo". Ao escrever sobre as características da vida popular na região da Sardenha passou a referenciá-la como parte das expressões socioculturais, econômicas e políticas que compõem o território italiano e o modo como este se relacionava internacionalmente (SIMIONATTO, 1995).

Para Gramsci, era evidente a unificação do simbólico/cultural com a sua materialidade socioeconômica e política, pois os legados históricos transpassam todas as lutas entre as classes em disputa por “hegemonia" na sociedade capitalista contemporânea, esfumaçando o aculturamento ocidentalizado de todas as expressões de resistência e modos de vida que não sejam aqueles mediados pelo liberalismo de mercado. Como autor marxista, de forte repercussão e vitalidade na análise da atualidade, estudou, aprofundou e se dedicou ao uso coerente do materialismo histórico e dialético no qual a história não é estática e nem está retida no passado, pois os legados culturais traduzem-na, atualizando práticas (conservadoras, progressistas e/ou revolucionárias) conforme o repertório político-econômico que marca os conflitos entre classes em determinado tempo (a filosofia é da práxis).

Na América Latina, a fragmentariedade e o acesso tardio aos escritos gramscianos transformaram o autor em um interlocutor restrito às vanguardas representantes da classe trabalhadora porque sua difusão ocorreu direcionada à formação política militante nos Partidos Trabalhistas argentinos, a partir da década de 1950. Porém, as dificuldades de tradução dos originais e o desconhecimento de muitos de seus escritos jornalísticos e políticos fomentaram análises reducionistas de suas categorias, especialmente num contexto de interpretações rígidas do materialismo histórico que subtraia a dialética e secundarizava a política na luta de classes sob a visão economicista/ etapista da revolução, empobrecendo a interpretação das ações humanas em sociedade (GUILHERME, 2008). 
Apenas a partir da década de 1970, na América, publicações e interpretações da obra gramsciana ocorreram de maneira mais fidedigna, tomando suas categorias sem tratá-las como cartilhas ou manuais no esforço de elaborar análises autorais sobre a realidade latino-americana (CUILHERME, 2008). Aguiar (2017) ressalta que o:

[...] marxismo na América Latina [...] lida com algumas dificuldades: o rompimento com o eurocentrismo, a análise da colonialidade, do nacionalismo e de sociedades de desenvolvimento desigual, e, não menos importante, a questão relacional entre raça e classe (e intrinsecamente a questão indígena). Isto não significa dizer, contudo, que são temas negligenciados pela perspectiva marxista, principalmente a partir de correntes e autores que expressam a ala revolucionária do marxismo frente às variantes reformistas e eurocentristas, tampouco significa cobrar a possibilidade de uma iniciativa intelectual de Marx e Engels em que os autores estudem definidamente a história das lutas de classes particulares de todos os países fora do circuito da Europa (AGUIAR, 2017, p. 16).

A referência à Gramsci nas "teorias pós-coloniais" ocorreu, inicialmente, por meio da apropriação de chaves analíticas sobre a relação "colonialidade-imperialismo" e sobre a "subalternidade". O exercício empreendido nas interpretações decoloniais sobre os povos originários e a constituição geopolítica da América Latina partiu da constatação de que:

[...] A colonização e o pensamento europeu trouxeram aos povos originários latino-americanos, não só a marca da dependência financeira, foram cruciais, sobretudo, a expansão de uma influência intelectual e um colonialismo cultural que, juntos com a propriedade privada, marcaram nossa formação econômico-social. Em contrapartida, há algumas décadas, um conjunto heterogêneo de forças políticas que se colocavam como alternativas ao neoliberalismo com um destacado protagonismo de movimentos sociais - a exemplo do levantamento zapatista em 
Chiapas, no México, bem como as inúmeras resistências contra o genocídio indígena que, ainda acontece no subcontinente - retoma as lutas pela autonomia das etnias, pela libertação nacional e pelo reconhecimento, junto a uma demanda por descolonização pela via democrática (ACUIAR, 2016a, p. 273-274).

Portanto, o "colonialismo cultural" foi interpretado como uma ideologia difundida de maneira organizada por meio do trabalho sistemático de diferentes grupos de intelectuais dedicados à constituição do consenso em torno do "bloco histórico" capitalista calcado sob a reprodução da subalternidade dos interesses dos povos originários ao poder hegemônico exercido pelos impérios colonizadores (ACUIAR, 2016a). Tarefas brilhantemente executadas pelos setores da Igreja Católica e, depois, por profissões como o serviço social.

$O$ aspecto cultural conservador veiculado pela prática desses profissionais só foi questionado em meados do século $X X$, em meio às ditaduras políticas, após o acesso de intelectuais e militantes à outras bases teóricas, dentre elas o marxismo. No período de resistência política às ditaduras na América Latina e de solidificação de bases teórico-metodológicas marxistas, ocorreu um intercâmbio no serviço social latino-americano que gestou projetos profissionais mais orgânicos às necessidades concretas das classes subalternas, dando-lhes voz (IAMAMOTO, CARVALHO, 2000).

Os processos de "reconceituação" no interior do serviço social latino-americano ampararam-se na interpretação crítica das fontes difusoras do materialismo histórico e dialético como método de análise e de ação na realidade. A incorporação de referenciais marxistas resultou num giro ídeo-político que direcionou a formação acadêmica e técnica para a base dos movimentos sociais urbanos e rurais, tentando exercitar a intelectualidade orgânica pelas pautas das classes subalternas. Nesse processo, o Serviço Social encontrou um marxismo vivo nos escritos gramscianos que deu suporte à categoria profıssional para elaborar interpretações autorais (IAMAMOTO, CARVALHO, 2000). 
As interpretações que beberam nos escritos de Gramsci sobre as "classes subalternas" como "potências revolucionárias" contribuíram, sobremaneira, para análises insurgentes sobre e a partir das lutas latino-americanas, fornecendo chaves analíticas que auxiliaram no reconhecimento das características particulares do território e da cultura próprias de um contexto de relações calcadas num tipo de desenvolvimento econômico cujas desigualdades implicaram necessariamente a segregação e a discriminação racial.

\section{Conclusões preliminares}

Ao considerarmos o Serviço Social na América Latina como uma profissão que segue exercendo a função de intelectual, hoje, formal e declaradamente orgânica às classes subalternas, consideramos também que as profissionais que a encarnam portam certa responsabilidade ético-política cuja visão de mundo não dicotomiza teoria e prática. Se para Gramsci (1999, p. 126) a "[...] tarefa dos intelectuais é determinar e organizar a reforma moral e intelectual, isto é, adequar a cultura à função prática [...]". O que se coloca em discussão aqui é que, no pensamento pós-colonial, existe uma tradução de pensamentos e de experiências históricas anteriores que não abdicaram do debate sobre questões especificas e caras às culturas latino-americanas.

A importância dos estudos decoloniais nesse debate reside no reconhecimento de um esforço intelectual de aproximação que ainda é necessário quando abordamos os problemas dos segmentos concretos que compõem o conjunto dos historicamente subalternizados na América Latina. Significa que, tanto as práticas profissionais como os esforços teóricos precisam lidar com um gigantesco conjunto de subalternizados (e essa é a expressão material e simbólica que pauta a questão social aqui existente). Portanto, pesquisas que queiram seguir nessa direção precisam atentar para pontos que auxiliam na compreensão e na ação sobre a questão social latino-americana, pois: 
- é incompreensível se não for mediada pela história colonial e suas heranças;

- é composta pelas resistências, contundentes em alguns países e regiões, de: indígenas, quilombolas, da presença de um tipo particular de campesinato, bem como abarca as relações socioculturais decorrentes desse embate e que, obviamente, estão ausentes nos estudos marxistas europeus;

- é portadora de especificidades nas relações sociais: as classes aqui não se configuram como cópias da realidade europeia, embora tenham se formado em uma realidade subordinada a ela. Importante considerar que aqui temos camponeses pobres que são levados a subordinar indígenas, assim como muitas outras camadas e (sub)divisões entre os subalternizados;

- possui um imaginário/conjunto de recursos de memória de resistências coletivas que é diferente do europeu, mas também encarna uma relação diferente com a ideia de "modernização". O subalterno aqui, quando resiste, não é em nome do "futuro do proletariado", mas em nome, muitas vezes, do resgate da liberdade do passado (Ex.: Mapuches nos Andes; diferentes etnias indígenas no México etc.).

Em que pese a incompletude dessa análise, entendemos que tanto a filosofia da práxis quanto os estudos decoloniais latino-americanos carecem de maior apropriação teórico-prática por parte da área de conhecimentos composta pelo serviço social, especialmente para compreender a "tradutibilidade" necessária entre bases sociais concretas e concepções de mundo que são semelhantes por partilhar princípios ético-políticos orgânicos às lutas por emancipação das classes subalternas. 


\section{Referências}

ACANDA, Jorge Luis. Sociedade Civil e Hegemonia. Rio de Janeiro: Ed. UFRJ, 2006. AGUIAR, Jórissa Danilla Nascimento. Entre a Subalternidade e o Socialismo Indoamericano: existe um pensamento marxista decolonial? 2018: 196f. Tese (Doutorado em Ciências Humanas) - Centro de Humanidades - Universidade Federal de Campina Grande (UFCG), Campina Grande, 2017. Disponivel em: 〈http://dspace.sti.ufcg.edu.br:8080/jspui/handle/riufcg/1324〉. Acesso em: 17 fev. 2021.

ACUIAR, Jórissa Danilla Nascimento. Por um Marxismo Decolonial: contribuições para a reflexão sociológica contemporânea. Revista Observatoria Latinoamericano y Caribeño, n. 2, pp. 58-68, 2018. Disponivel em: < https:// publicaciones.sociales.uba.ar/index.php/observatoriolatinoamericano/article/view/2784>. Acesso em: 17 fev. 2021.

ACUIAR, Jórissa Danilla Nascimento. Teoria Pós-Colonial, Estudos Subalternos e América Latina: uma guinada epistemológica. Revista Estudos de Sociologia, Araraquara, v. 21, n. 41, pp. 273-289, jul-dez, 2016a. Disponivel em: <https://periodicos.fclar.unesp.br/estudos/article/view/8659>. Acesso em: 17 fev. 2021.

AGUIAR, Jórissa Danilla Nascimento. Grupos Socias Subalternos e a Disputa por Hegemonia: apontamentos gramscianos. In: JORNADA INTERNACIONAL DE ESTUDOS E PESQUISA EM ANTONIO GRAMSCI, 1, 2016, Anais...Fortaleza: 2016b. pp. 01-17. Disponível em: http://www.ggramsci.faced.ufc.br/anais-i-gt5.

BALLESTRIN, Luciana Maria de Aragão. América Latina e Giro Decolonial. Revista Brasileira de Ciência Política, Brasília, n.11, pp. 89-117, maio-agosto, 2013. Disponível em: <https://periodicos.unb.br/index.php/rbcp/article/ view/2069>. Acesso em: 17 fev. 2021.

BALLESTRIN, Luciana Maria de Aragão. Modernidade/Colonialidade sem "Imperialidade"? o elo perdido do giro decolonial. Revista Dados, Rio de Janeiro, v. 60, n.21, pp. 505-540, abri-jun, 2017. Disponivel em: http://dados. iesp.uerj.br/artigos/?id=1081. Acesso em: 17 fev. 2021.

BOOTHMAN, Derek. Verbetes: "tradução" e "tradutibilidade". In: LIGUORI, Guido; VOZA, Pasquale (Org.). Dicionário Gramsciano (1926-1937). 1 ed. São Paulo: Boitempo, 2017, pp. 779-784. Tradução: Ana Maria Chiarini, Diego Silveira Coelho Ferreira, Leandro de Oliveira Galastri e Silvia De Bernardinis. Revisão técnica: Marco Aurélio Nogueira. 
CAPONI, S. Da Compaixão à Solidariedade: uma genealogia da assistência médica. Rio de Janeiro: Editora Fiocruz, 2000.

CASTRO, M. M. História do Serviço Social na América Latina. 2 ed. São Paulo: Cortez, 1987.

CHABALGOITY, Diego. O Estudo da Ontologia do Oprimido: do simples entrelaçamento de correntes filosóficas à tradutibilidade gramsciana e decolonial. In: LOLE, Ana (Org.). O Fermento de Cramsci na nossa Filosofia, Política e Educação. Rio de Janeiro: Mórula, 2018.

DIAS, Edmundo Fernandes. A Revolução Russa vista por Gramsci. In: LOLE, Ana; GOMES, Victor L. C.; DEL ROIO, Marcos (Org.). Cramsci e a Revolução Russa. 1. ed. Rio de Janeiro: Mórula, 2017, pp. 59-90.

GRAMSCI, Antonio. Cadernos do cárcere. Vol. 1: Introdução ao estudo da filosofia - a filosofia de Benedito Croce. Edição e tradução Carlos Nelson Coutinho; coedição Luiz Sérgio Henriques e Marco Aurélio Nogueira. Rio de Janeiro: Civilização Brasileira, 1999.

GUILHERME, Cássio Augusto S. A. Gramsci na América Latina: história de uma recepção. In: Simpósio de lutas sociais na América Latina, 3, 2008, Londrina. Anais...Londrina: 2008. pp. 01-14. Disponível em: http://www.uel.br/grupo-pesquisa/gepal/terceirosimposio/cassio_augusto.pdf. Acesso em: 16 fev. 2021.

IAMAMOTO, Marilda; CARVALHO, Raul de. Relações sociais e Serviço Social no Brasil. 13 ed. São Paulo: Cortez; Lima/Peru: CELATS, 2000, pp. 213-234.

KINSERMANN, N. O Processo Histórico do Serviço Social. In: KINSERMANN, N. Introdução ao Trabalho Social. São Paulo: Moraes, 1983.

LACORTE, Rocco. Liberdade e Tradutibilidade nos Cadernos de Gramsci. Revista Práxis e Hegemonia Popular, n² 2, pp. 47-80, jul, 2017. Disponível em: https://revistas.marilia.unesp.br/index.php/PHP/article/view/10546. Acesso em: 06 mar. 2021.

LOSURDO, Domenico. Contra-história do liberalismo. Aparecida/SP: Ideias \& Letras, 2006.

MARTINELLI, Maria L. Serviço Social: identidade e alienação. 6.ed. São Paulo, Cortez, 1997.

NEVES, Rita Ciotta. A Perspectiva Pós-Colonial de Antonio Gramsci: os subalternos. Revista Babilônia, n. 8-9, pp. 59-64, 2010. Disponivel em: https:// www.redalyc.org/pdf/561/56118082005.pdf. Acesso em: 19 fev. 2021. 
PINTO, Otávio Luiz Vieira. História da África l: pós-colonial, decolonial, subalterno. Youtube, 16 de novembro, 2020. Disponivel em: <https://www.youtube. com/watch?v=relJEPzGifA\&list=WL\&index=14>. Acesso em: 05 mar. 2021.

SADER, Emir. Século XX uma Biografia Não Autorizada: o século do Imperialismo 1. reimpressão. São Paulo: Ed. Fundação Perseu Abramo, 2000.

SIMIONATTO, Ivete. Gramsci: sua teoria, incidência no Brasil, influência no Serviço Social. Florianópolis: Ed. Da UFSC; São Paulo: Cortez, 1995.

\section{Notas}

1 Graduando em Serviço Social, Faculdade de Serviço Social (FSSO), Universidade Federal de Alagoas/Maceió (UFAL). Membro Grupo de Pesquisa e Extensão: Políticas públicas, Controle Social e Movimentos Sociais. Brasil. ORCID https:// orcid.org/0000-0002-8122-9143 E-mail: joelcio.silva@fsso.ufal.br

2 Doutora em Serviço Social pela Universidade Federal de Santa Catarina (UFSC). Professora adjunta e coordenadora de extensão na Faculdade de Serviço Social (FSSO), Universidade Federal de Alagoas/Maceió (UFAL). Vice-líder Grupo de Pesquisa e Extensão: Políticas públicas, Controle Social e Movimentos Sociais. Brasil. ORCID https://orcid.org/0000-0002-7897-7722 E-mail: telma.lima@fsso.ufal.br

3 Doutor em Serviço Social pela Universidade Federal do Rio de Janeiro (ESS-UFRJ). Professor adjunto do Instituto de Relações Internacionais e Defesa (IRID), Universidade Federal do Rio de Janeiro (UFRJ), coordenador do Observatório de Política e Economia Contemporâneas e Violações de Direitos Humanos (OPECDH). Brasil. ORCID https://orcid.org/0000-0001-9337-8034 E-mail: elidioalexandre@yahoo.com.br

4 A preocupação sobre os aspectos culturais de um povo/Nação absorveu Gramsci a partir da instauração do Regime Fascista Italiano, inquietava-Ihe o fato de que - mesmo diante de avanços sociais, políticos e técnicos - os indivíduos, grupos e corporações seguiam aderindo e trabalhando ativamente na disseminação de regimes totalitário cuja arma mais eficiente estava na propaganda que cultivou o fascismo pelo convencimento cultural da existência de uma superioridade regional e racial (SIMIONATTO, 1995).

5 O marco inicial foi a publicação do livro "Neocolonialismo: último estágio do imperialismo" (1965) de Kwame Nkrumah (1909-1972). Os escritos da fase, variam entre discursos políticos e literários, que partiam de pensadores latino-americanos, africanos e europeus para entender o processo de independência e decidir sobre os novos caminhos. Nomes marcantes: Amílcar Cabral (1934- 
1973), Che Guevara (1928-1967), Frantz Fanon (1935-1961), Ho Chi Minh (18901969), Jean-Paul Sartre (1905-1980), Aimé Césaire (1913-2008) e Albert Memmi (1920-2020) (BALLESTRIN, 2017).

6 A obra "Orientalismo" (1978) de Edward Said (1935-2003) é considerada o marco inaugural e expôs a invenção europeia do Oriente como estratégia de manutenção do poder colonial/imperial oriunda da mundialização ocidental e genocida de diferentes países da Europa. Além de Said, destacaram-se também como autores que representam essa fase: Gayatri Spivak (1942), Paul Gilroy (1956), Stuart Hall (1932-2014) e Homi Bhabha (1949) (BALLESTRIN, 2017).

7 Havia críticas às análises desse grupo de estudos devido a aparente desconexão com a realidade social latino-americana, faltavam-lhes o estudo de aspectos concretos gerados pela dependência econômica. Isso requeria, inevitavelmente, algum questionamento das ideologias eurocêntricas. São referências: a obra "Colonialidad y modernidad-racionalidad" em 1992, do sociólogo peruano Aníbal Quijano" e, depois, "em 1995 a publicação do 'Manifesto inaugural' do grupo" que inseriu as suas produções sobre as características do subcontinente no debate pós-colonial existente (AGUIAR, 2016b, p. 12).

8 Os principais autores dessa fase são: Aníbal Quijano (1928-2018), Enrique Dussel (1934) e Immanuel Wallerstein (1930-2019), seguido pelas demais referência de Walter Mignolo (1941), Ramón Grosfoguel (1956), Nelson Maldonado-Torres, Catherine Walsh, Santiago Castro-Gómez (1958), Eduardo Restrepo, Arthuro Escobar (BALLESTRIN, 2017). 